\title{
Experimental study of the addition of oil palm mesocarp fiber on the physical and mechanical properties of fiber cement mortar composites
}

\author{
Christian Bopda Fokam ${ }^{1}$ (D) $\cdot$ Eric Toumi $^{1} \cdot$ Bienvenu Kenmeugne $^{1} \cdot$ Nfor Clins Wiryikfu $^{1,2} \cdot$ Lucien Mevaa $^{1}$
}

Received: 16 August 2020 / Accepted: 21 December 2020 / Published online: 11 January 2021

(c) The Author(s) 2021 OPEN

\begin{abstract}
Composite materials based on natural fibers are increasing in demand in various sectors of industry because of their interesting specific properties. This work is a contribution to the valorization, of plant fibers from agricultural plantations in Cameroon, in fiber cement mortar (FCM). This paper studies the influence of the addition of oil palm mesocarp fiber (OPMF) on the physical (water absorption, density and compactness) and mechanical (compressive strength and flexural strength) properties of cement mortars. The fibers used in this paper are extracted from oil palm mesocarp (palm kernel pulp) by a mechanical and manual process. Cement mortar specimens were then made with different proportions of fibers: $0 \%$ (reference mortar), $1 \%, 2 \%, 3 \%$ and $3.5 \%$ fibers. Physical and mechanical tests are then carried out on our specimens. Regardless of the duration of immersion in water, the results show that the water absorption rate increases with a greater amount of fiber in the FCM specimens. On the other hand, an inverse effect is observed on density, which decreases from 2277.5 (samples with $0 \%$ fiber) to $942.1 \mathrm{~kg} / \mathrm{m}^{3}$ (samples with $3.5 \%$ fiber) for apparent density and from 2641.2 to $1945.7 \mathrm{~kg} / \mathrm{m}^{3}$ for absolute density. On the mechanical properties, there is a steady decrease in compressive strength from 42.47 (for the reference mortar at $0 \%$ fiber) to $31.1 \mathrm{MPa}$ (for the sample at 3.5\% fiber). In bending, there is first an increase and then a decrease in strength with the amount of fibers. The maximum flexural strength is obtained for a $2 \%$ fiber composition. The FCM has a better strength/density ratio. Finally, the addition of OPMF, in small proportion in the cement mortar, allows a lightening of the structure, but induces a small decrease in mechanical resistance. Our FCM can be used in the manufacture of cinderblocks or as internal wall roughcoating mortar.
\end{abstract}

Keywords Fiber cement mortar · Oil palm mesocarp fiber · Water absorption · Density · Mechanical properties

\section{Introduction}

Cement mortar reinforced with fiber is applied in the domain of infrastructure, renovation works and building of houses [1-4]. The uniqueness of its mixture makes this mortar a material with good mechanical characteristics especially in terms of durability. This mortar is made up of synthetic fibers, cements and siliceous sands. A reduction in natural deposits especially oil and an increase in the knowledge of pollution from the application of synthetic fibers $[5,6]$ has increased an interest in fibers from natural origin, renewable and biodegradable resources. For business purposes, studies done on fibers are mainly concerned with industrially produced plants like flax, hemp, palm kernel, cotton, banana, etc. [7-9].

Composites reinforced with natural fibers occupy among the highest area of research nowadays. Çomak et al. [10] have evaluated the effects of hemp fibers on

Christian Bopda Fokam, fokam79@gmail.com | 'Laboratoire en Engineering Civil et Mécanique, National Advanced School of Engineering of Yaoundé (ENSPY/UY1), University of Yaoundé 1, P.O. Box: 8390, Yaoundé, Cameroon. ${ }^{2}$ Local Material Promotion Authority (MIPROMALO), Yaoundé, Cameroon. 
the characteristics of mortar from cement. In their studies, they mixed cement mortar with hemp fiber in different formulations $(0 \%, 1 \%, 2 \%$ and $3 \%)$ and lengths $(6 \mathrm{~mm}, 12 \mathrm{~mm}$ and $18 \mathrm{~mm}$ ). From their results, they proved that, $12 \mathrm{~mm}$ lengths, reinforced with 2-3\% cement mortars provided the most important results. Danso et al. [11] studied the influence of lime and fibers of coconut on the properties of cement-soil mortar. From their studies they concluded that coconut fibers and lime positively affect the characteristics of cement-soil mortars for use with the highest strength noted at $0.2 \%$ fiber and $5 \%$ lime addition on the sample.

Kesikidou et al. [12] have carried out studies on natural fiber reinforced mortars and the results gave more lights on the application of natural (bio) fibers in construction materials to promote the reuse of bio-fibers in the construction sector. In their studies, they used three types of vegetal fibers (coconut, kelp and jute) as additives and $1.5 \%$ mortar by volume. Ramakrishna et al. [13] carried out studies on the effects of natural fiber-reinforced cement mortar slabs and proved that adding coconut fibers from 0.5 to $2.5 \%$ highly increased the impact resistance of slabs. Vantadori et al. [14] studied date palm fibers-reinforced mortars and concluded that adding the quantity of fiber increased the ratio of ductility and weight of the cement mortar.

Vegetal fibers used in this paper are oil palm mesocarp fiber from Cameroon, precisely from the West Region and are extracted from the specie of palm oil called E-Elaeis guineensis using a set of procedures having several steps; mechanical washing and drying [15]. Palm oil is responsible for a very important part of activities in the agricultural sector in Cameroon. It is mostly planted for the oil of its nuts. Waste like husk from rice and mesocarp fibers from palm oil are mostly thrown into the wild or burnt. The study in this paper seeks to look at ways to give value to this waste so as to offer cultivators an added economic advantage. Normally, the domain of construction has to promote the valorization of biomass fibers and recycling in a quest to solve problems linked to the environment. In Africa, vegetal fiber-reinforced earth mortars still have a wide application in the construction sector (cob, adobe, etc.). However, the mortar matrix from cement remains the basic building material in towns.

In this article, the focus is on the possibility of using oil palm nut fibers from Cameroon to reinforce cement mortars in order to produce cinderblocks as a sustainable replacement for conventional cinderblocks. The aim of the study is to evaluate the influence of adding oil palm mesocarp fiber (OPMF) on the mechanical characteristics of cement mortar. We start by forming reinforced fiber cement mortar samples following recommended standards. The fiber content of OPMF in FCM ranges from 0 to $3.5 \%$.

\section{Materials and methods}

\subsection{Materials}

The natural fibers that are the subject of this manuscript come from the oil palm, variety E Elaeis guineensis, from the town of BAZOU, West Region of Cameroon (Fig. 1). The fibers valued in this study are extracted from oil palm mesocarp fiber (OPMF) (Fig. 1d).

A hydraulic press is used to extract oil from the OPMF. At the exit of the press, the oilcake is made of a very dense mixture of fibers and palm nut (Fig. 2a). The fibers, which are manually cleared from the nuts and some pulp particles, are washed at a temperature of $70^{\circ} \mathrm{C}$ and then dried (Fig. 2b, c). Figure 2 shows the pictures of the oilcake and the state of the fibers at different stages of extraction. The mechanical extraction process used in this paper increases the roughness of the outer surface of the fibers and contributes to a better fiber/matrix adhesion [16] (see Table 1).

\subsection{Elaboration of fiber-cement mortar (FCM) sample}

After removal of oil from the palm nuts, the remaining fiber waste will be used to make the FCM samples. The

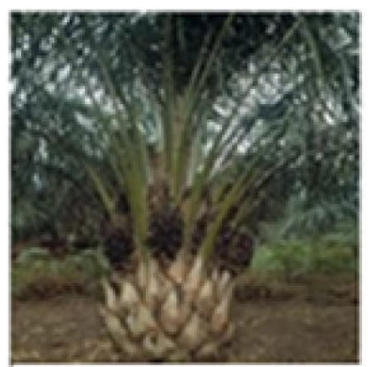

(a)

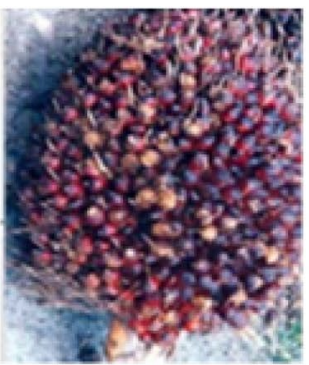

(b)

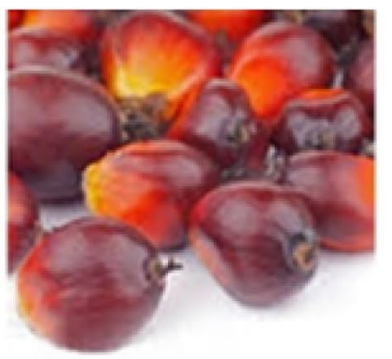

(c)

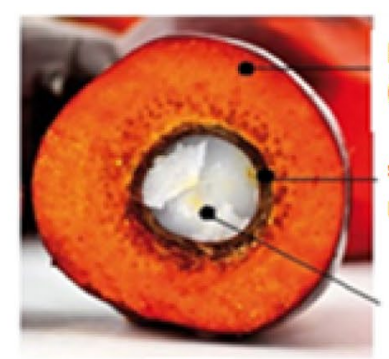

Pulp

(Mesocarp)

shell of palm nut (endocarp)

Palm nut

Fig. 1 Oil palm: a oil palm tree, b regime of oil palm, $\mathbf{d}$ palm nut, $\mathbf{c}$ palm kernel cross section 


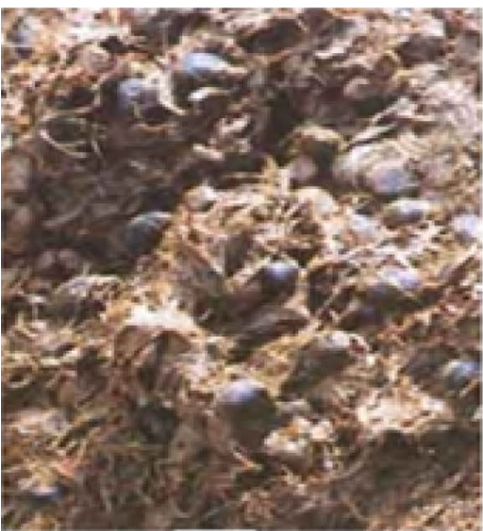

(a)

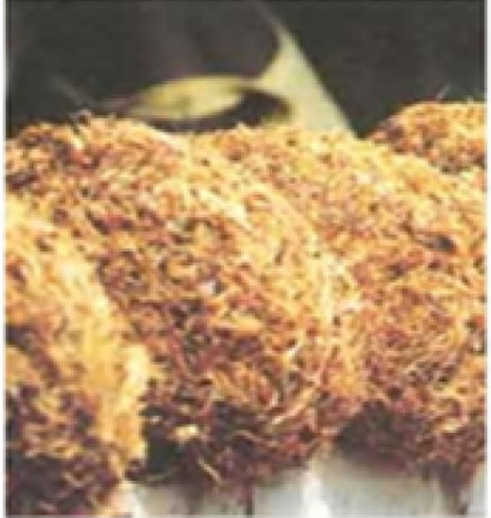

(b)

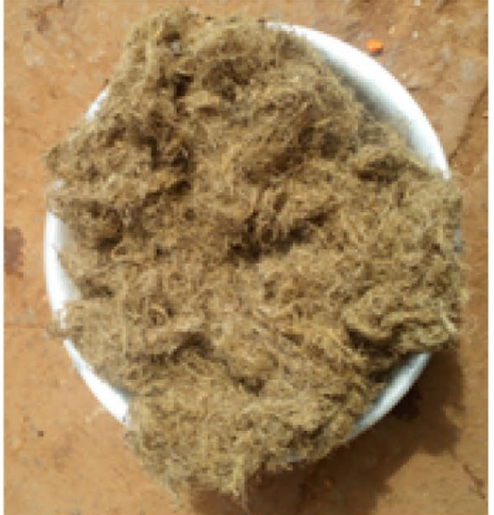

(c)

Fig. 2 Fibers states after extraction from hydraulic press: a waste OPMF, $\mathbf{b}$ cleaned raw fibers

Table 1 Average size of fibers

\begin{tabular}{lc}
\hline Designation & Value $(\mathrm{mm})$ \\
\hline Lengths & $24-49$ \\
Radius & $0.16-0.87$ \\
\hline
\end{tabular}

final product is a dimensionally standardized brick of natural short fiber-reinforced cement mortar (Fig. 3). The test specimens thus made are as follows:

- Sand: River sand (YONG River) from Cameroon's Central Region (City of Mbalmayo). The sand used has a granulometry of 0/2 according to standard NF EN 196-1 (Sand $0-2 \mathrm{~mm}$ ).

- Cement: Cement type CEMI BP42.5R according to standard NC 234: 2009-06 (Manufactured by the company DANGOTE CEMENT - Cameroon).

- Short fibers: Natural fibers waste from the extraction of palm nut pulp (Fiber density: $521 \mathrm{~kg} / \mathrm{m}^{3}$ ).

- The mixing water is free of impurities in accordance with standard NF P 18-303 (Water/cement ratio=0.6).

The FCM specimens shall be prismatic in shape and shall have a size of $40 \mathrm{~mm} \times 40 \mathrm{~mm} \times 160 \mathrm{~mm}$ (volume:
256.10-6 $\mathrm{m}^{3}$ ) for the flexural test. The dimensions for compression test are: $40 \mathrm{~mm} \times 40 \mathrm{~mm} \times 80 \mathrm{~mm}$. The manufacture and dimensions of the FCM specimens are carried out according to the European standard NF EN 196-1. This standard details the methodology to be followed for the preparation and determination of the mechanical properties of cement mortars. Figures 3 and 4 show respectively the stages of preparation and an image of the sample. Table 2 shows the designation and the fiber composition of the various manufactured samples.

\subsection{Water absorption}

The experimental protocol for measuring the water absorption of FCM samples is carried out after determining the dry mass of the specimens (drying operation in an oven at $105^{\circ} \mathrm{C}$ for about $24 \mathrm{~h}$ ). After this step, the protocol is as follows:

- Immersion of the test specimen in a water tank (the samples are previously dried $\mathrm{M}_{105^{\circ} \mathrm{C}}$ to $105^{\circ} \mathrm{C}$ ).

- Weighing each test specimen at $x$-day increment: $M_{x D a y}$ ( $x$ equal a value between 1 and 21 days).
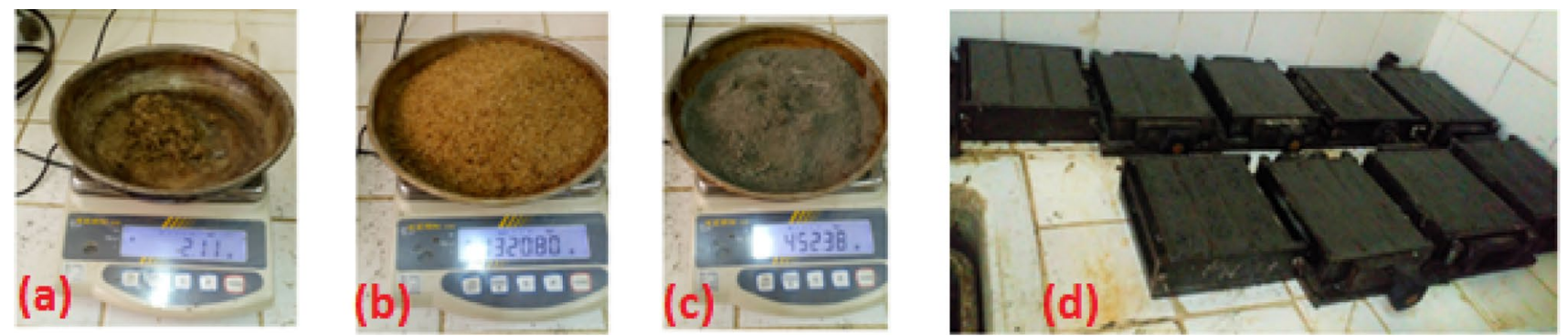

Fig. 3 Steps in the elaboration of fibro-cement mortar (FCM) samples (weighing and filling of moulds). Weighing of the different components of the sample $\mathbf{d}$ fiber cement mortar: $\mathbf{a}$ fiber, $\mathbf{b}$ sand, $\mathbf{c}$ cement 

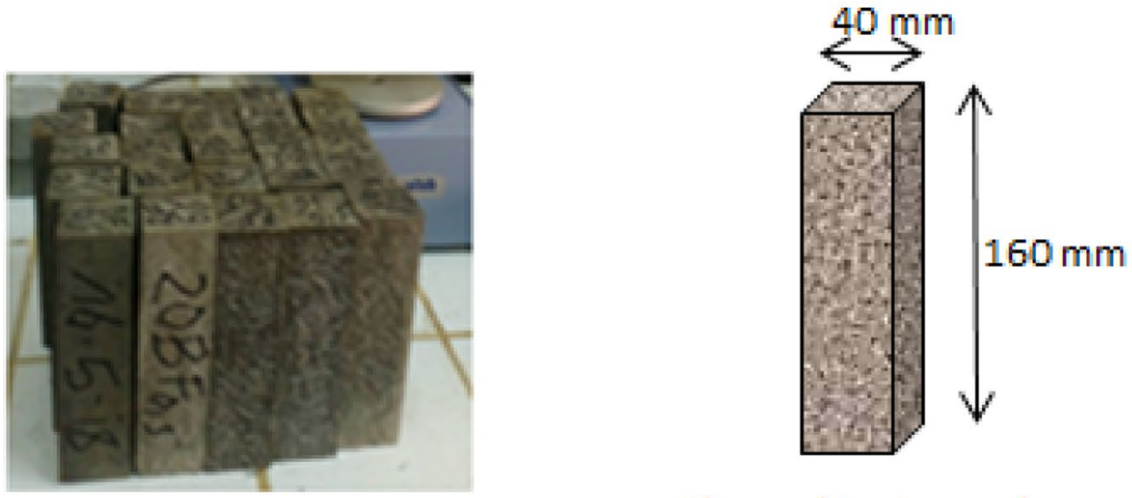

Compressive test sample

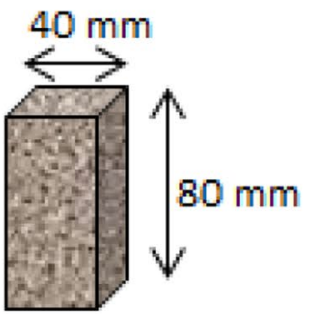

\section{Flexural test sample}

Fig. 4 Test specimen: dimensions cement mortar reinforced with OPMF

Table 2 Fiber composition of different FCM specimens

\begin{tabular}{ll}
\hline Designation & $\begin{array}{l}\text { Percentage of fibers } \\
\text { (volume fraction fiber) } \\
(\%)\end{array}$ \\
\hline MF0 & 0 \\
MF0.5 & 0.5 \\
MF1 & 1 \\
MF2 & 2 \\
MF3 & 3 \\
MF3.5 & 3.5 \\
\hline
\end{tabular}

- The operation ends when the saturation mass is reached $\mathrm{M}_{\text {sat }}$ (after 21 days).

$T A=\frac{M_{x D a y}-M_{105^{\circ} \mathrm{C}}}{M_{\text {xDay }}} \times 100$.

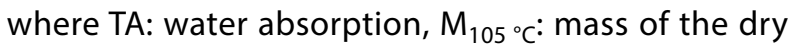
test specimen (in grams) after drying at $105^{\circ} \mathrm{C}, \mathrm{M}_{\mathrm{xDay}}$ : mass of the specimen, after a stay of " $x$ days" in the water tank, $\mathrm{M}_{\text {sat: }}$ : saturation mass ( $\mathrm{g}$ ): mass corresponding to a nearly zero mass variation (TA is maximal for $M_{\text {x Jours }}=M_{\text {sat }}$.

\subsection{Density of sample}

The dry density of the sample is determined following the protocol presented in the standard BS EN 771-1.The bulk density is calculated using the following standard equation (Eq. 2):

$\rho_{\text {App }}=\frac{M_{105^{\circ} \mathrm{C}}}{V}$. where $\mathrm{M}_{105^{\circ} \mathrm{C}}$ : dry mass of the sample in $\mathrm{kg}$ (measured after drying in an oven at $105^{\circ} \mathrm{C}$. for about $24 \mathrm{~h}$ ), V: Specimen volume $\left(\mathrm{m}^{3}\right)$.

The absolute density is measured by the graduated funnel method. The FCM sample is crushed and introduced into a graduated funnel where we successively measure the initial volume $V_{1}$ and the final volume $V_{2}$.

$\rho_{\text {Abs }}=\frac{M_{105^{\circ} \mathrm{C}}}{V_{2}-V_{1}}$

where $M_{105^{\circ}} \mathrm{c}$ : dry mass of the sample in $\mathrm{kg}$ (measured after drying in an oven at $105^{\circ} \mathrm{C}$. for about $24 \mathrm{~h}$ ), $\mathrm{V}_{1}$ : Initial water volume in the graduated funnel $\left(\mathrm{m}^{3}\right), \mathrm{V}_{2}$ : Final water volume after immersion of the sample $\left(\mathrm{m}^{3}\right)$.

\subsection{Compression machine}

A numerically controlled compression machine of CONTROLAB type, equipped with a data acquisition system, was used in this study. Using an appropriate fixation system, this device is also used for 3-point bending tests. The dimension and forms of the samples used are illustrated in the Fig. 4.

\section{Results and discussions}

In this section, we present the results and analyses of the tests carried out on specimens of fiber-reinforced cement mortar (with different amounts of fibers).

\subsection{Influence of the quantity of fiber on water absorption of the FCM}

Figure 5 shows the influence of the quantity of fibers on the water absorption of the different FCM samples. Regardless of the quantity of fibers in the FCM, it can be 
seen in Fig. 5a that water absorption increases with the time of immersion in water. Beyond a period of about 5 days, this value tends towards a threshold, corresponding to water absorption at saturation. In Fig. $5 \mathrm{~b}$, it is clearly seen that the quantity of fiber in the specimen affects the water absorption. As the quantity of fibers in the mortar increases, the water absorption increases. In fact, the water absorption increases from $2.63 \%$ for the reference sample ( $0 \%$ fiber) to $4.3 \%$ for the sample containing $3.5 \%$ fibers. This observation of the influence of fibre quantity on the water absorption is confirmed by other studies in the literature. Raut et al. [17] have shown that for an

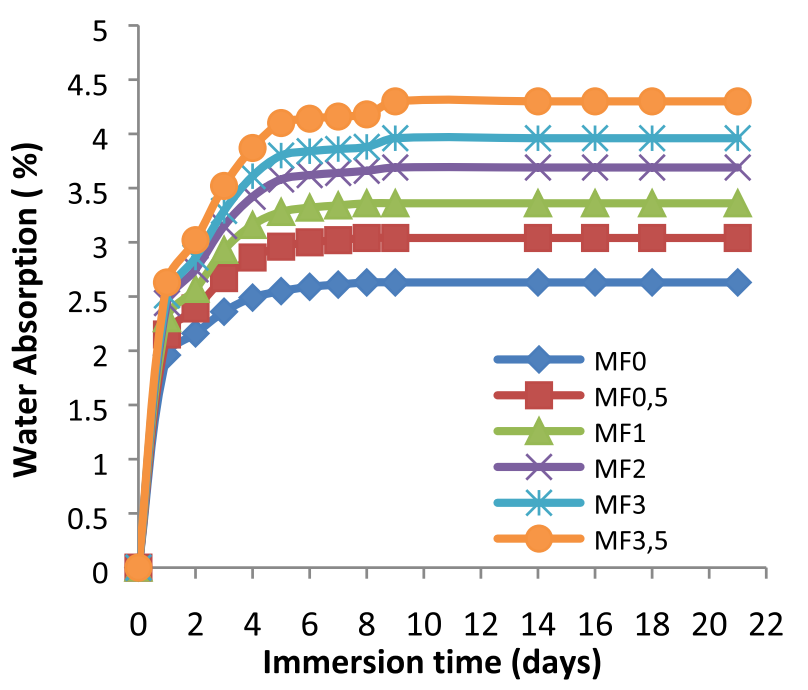

(a)

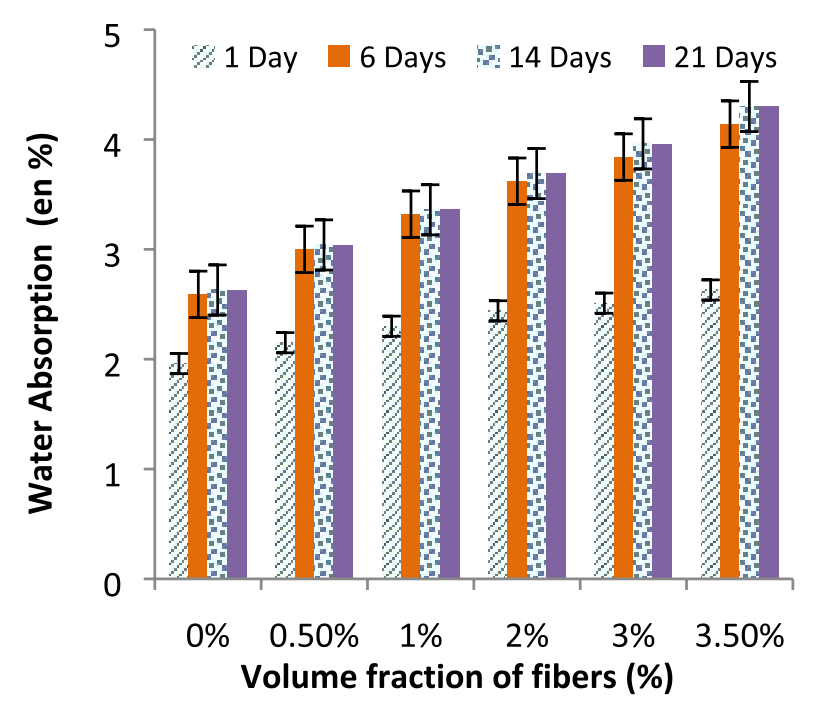

(b)

Fig. 5 a Variation of the water absorption as a function of the immersion time in water, $\mathbf{b}$ variation of the water absorption as a function of the quantity of fiber (saturation water absorption rates correspond to 21-day histograms) increasing proportion of oil palm fibre from 0 to $1.5 \%$, the mortar specimen has a higher water absorption. A slightly increasing water absorption, with the hemp fiber content (1-3\% fiber) in the cement mortar, was also obtained by Comak [10]. Studies by Danso et al. [11] on a coconut fiberreinforced cement mortar ( $0-0.8 \%$ fiber) clearly show an increase in water absorption with increasing fiber content.

\subsection{Influence of the quantity of fiber on the density of the FCM}

This paragraph presents the study of the influence of fiber quantity on sample densities (bulk density and absolute density).

Figure 6 shows the results of the variation of the density as a function of the quantity of fibers. It can be seen in Fig. 6 that densities (apparent and absolute) decrease gradually with the addition of a significant quantity of fibers to the sample. The apparent density decreases from $2277.5 \mathrm{~kg} / \mathrm{m}^{3}$ for the reference sample ( $0 \%$ fiber) to $942.1 \mathrm{~kg} / \mathrm{m}^{3}$ for the sample with $3.5 \%$ fibers. The absolute density decreases from $2641.2 \mathrm{~kg} / \mathrm{m}^{3}$ (for the $0 \%$ fibers sample) to $1945.7 \%$ (for the $3.5 \%$ fibers sample). The addition of fibers in the cement mortar makes it lighter. This shape is similar to that obtained by Vantadori [14] and Raut [17] who worked on cement mortars successively reinforced by date and oil palm fibers. In the work of Raut et al. [17], the density decreases from about 1900-1600 kg/ $\mathrm{m}^{3}$ respectively for an increasing proportion of oil palm fiber from 0 to $1.5 \%$. The decrease in density is partly due to the increase in porosity inherent to the cellular structure of the fibres [14].

The compactness corresponding to the ratio of the bulk density and the absolute density of the samples is calculated as shown in Fig. 7 below (Compactness $=100$ * $\left.\left[\rho_{\text {App }} / \rho_{\text {Abs }}\right]\right)$.

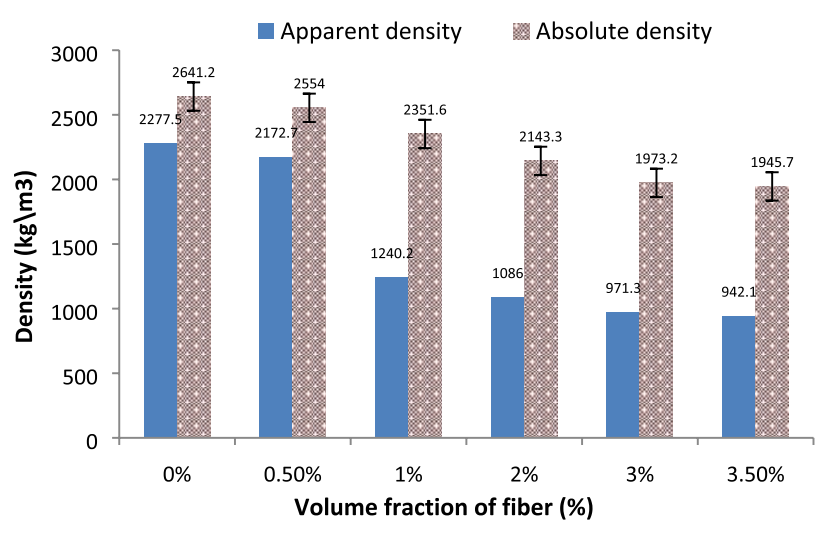

Fig. 6 Variation of the density with the quantity of fibers 


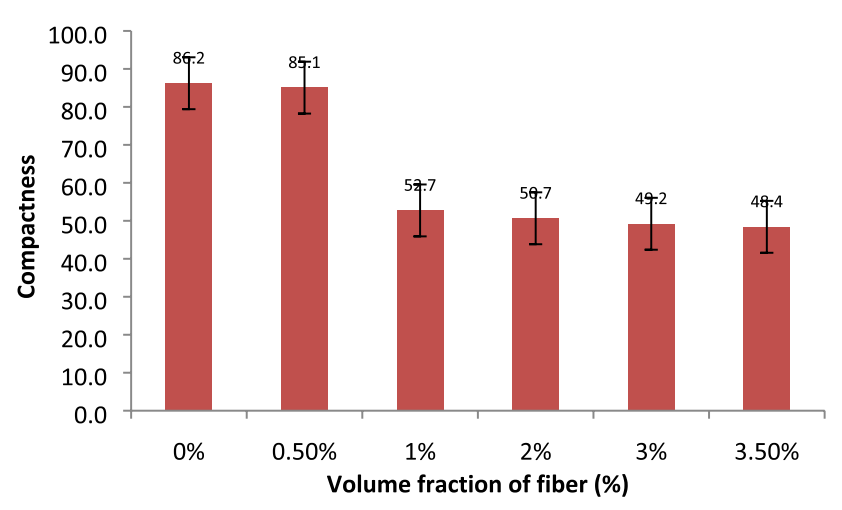

Fig. 7 Variation of the compactness with the quantity of fibers

The compactness as a function of the fiber load is shown in Fig. 7. We observe that the bars decrease progressively. The increase of fibers in the cement matrix tends to increase the quantity of micro vacuum in the mortar structure. The fibers are likely to absorb a certain quantity of water.

\subsection{Mechanical properties}

The results of the mechanical properties of FCM specimens are discussed in this section. The results in Fig. 8 are obtained from the compression test and three-point bending tests under monotonic loading until failure of the different FCM. The test specimens tested all have a maturity of 28 days.

Figure 8a shows the influence of the addition of fibers on the compressive strength. A progressive decrease in compressive strength is observed from 42.4 ( $0 \%$ fiber mortar) to $31.1 \mathrm{MPa}$ (3.5\% fibers mortar). For a fiber composition of 0 and $3.5 \%$ the loss of compressive strength is about $27 \%$. The results obtained by Comak et al. [10] show a (less regular) decrease in the compressive strength of hemp fibre-reinforced mortar. On the other hand, the work of Raut et al. [17] on FCM mortar reinforced with oil palm fibre confirms a progressive decrease in compressive strength (from 50 to $30 \mathrm{MPa}$ ) with the quantity of fibres in the proportions from 0 to $1.5 \%$.

Figure $8 \mathrm{~b}$ shows the influence of the addition of fiber on the flexural strength. Initially, an increase in flexural strength is observed, reaching a maximum value of 10.78 MPa for a mortar of about $2 \%$ fibers. In a second step, beyond $2 \%$ fibers, a decrease in flexural strength is observed. The flexural tests of Raut et al. [17] on oil palm fiber-reinforced FCM show a similar evolution of flexural strength to our observations, with maximum flexural strength values of $6.2 \mathrm{MPa}$ and minimum flexural strength values of $4.1 \mathrm{MPa}$. Regardless of the length of the hemp fibres used in the FCM, the results of Comak

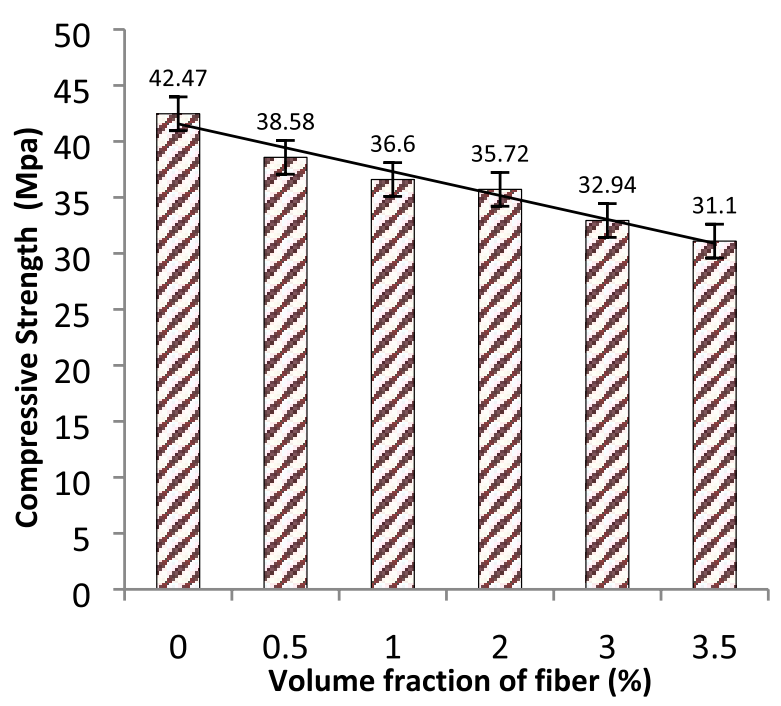

(a)

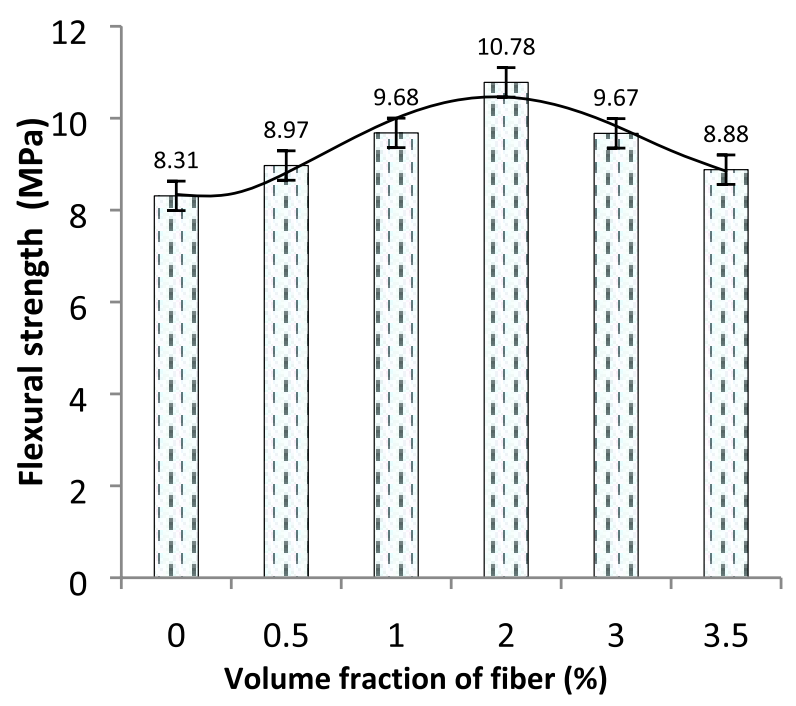

(b)

Fig. 8 For maturation time of 28 days cement mortar: a evolution of the compressive strength as a function of the quantity of fibers, b evolution of the flexural strength as a function of the quantity of fibers

et al. [10] show the same shape in flexural strength as a function of the hemp fibre content.

Figure 9 shows a correlative evolution between the mechanical resistances (flexural and compression) and the density of the different samples of FCM. Overall from Fig. 9a, it can be seen that the mechanical properties decrease with decreasing density (despite a slight increase in flexural strength). Nevertheless, if we consider the strength-to-density ratio in Fig. 9b, we can see 


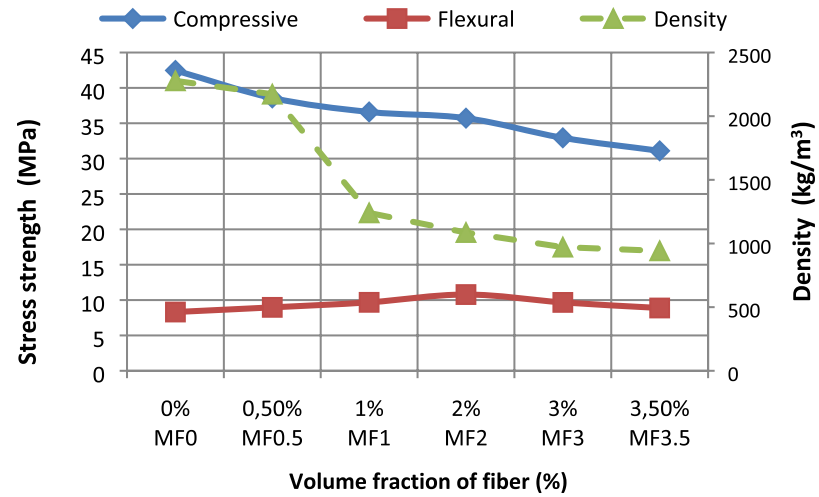

(a)

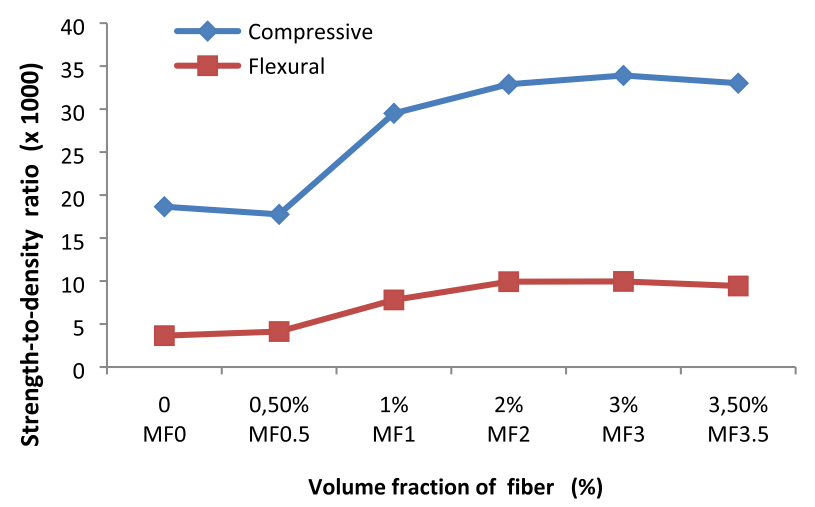

(b)

Fig. 9 a Correlation between the evolution of mechanical resistance and density of samples, $\mathbf{b}$ evolution of the ratio mechanical resistance/density as a function of fiber quantity

that increasing the amount of fibers in the FCM improves the strength-to-density ratio.

\section{Conclusion}

This paper presented an experimental study of the influence of the quantity of OPMF on the physical and mechanical properties of cement mortar.

FCM test specimens, with standardized dimensions, were made containing variable proportions of short fibers of oil palm mesocarp (between 0 and $3.5 \%$ fibers). The specimens were then tested to determine certain physical (density, absorption rate) and mechanical (flexural and compressive strength) characteristics. The results showed that the addition of fibers allows a decrease in weight of the cement mortar and overall a slight decrease in mechanical resistance. However, considering the mechanical strength/density ratio, it was found that samples containing a higher proportion of fibers were superior to the reference mortar samples ( $0 \%$ fiber).
Acknowledgements The authors would like to thank the LABOGENIE (National Civil Engineering Laboratory) and some oil palm producers, respectively for access to their documentation and plant raw material.

\section{Compliance with ethical standards}

Conflict of interest On behalf of all authors, Christian Bopda Fokam states that there is no conflict of interest.

Open Access This article is licensed under a Creative Commons Attribution 4.0 International License, which permits use, sharing, adaptation, distribution and reproduction in any medium or format, as long as you give appropriate credit to the original author(s) and the source, provide a link to the Creative Commons licence, and indicate if changes were made. The images or other third party material in this article are included in the article's Creative Commons licence, unless indicated otherwise in a credit line to the material. If material is not included in the article's Creative Commons licence and your intended use is not permitted by statutory regulation or exceeds the permitted use, you will need to obtain permission directly from the copyright holder. To view a copy of this licence, visit http://creativecommons .org/licenses/by/4.0\%.

\section{References}

1. Lau KT, Hung PY, Zhu MH, Hui D (2018) Properties of natural fiber composites for structural engineering applications. Compos B Eng 136:222-233. https://doi.org/10.1016/j.composites b.2017.10.038

2. Moses OT, Samson D, Waila OM (2015) Compressive strength characteristics of kenaf fibre reinforced cement mortar. Adv Mater 4(1):6-10. https://doi.org/10.11648/j.am.20150401.12

3. Schiavoni S, D'Alessandro F, Bianchi F, Asdrubali F (2016) Insulation materials for the building sector: a review and comparative analysis. Renew Sustain Energy Rev 62:988-1011. https://doi. org/10.1016/j.rser.2016.05.045

4. Yakum R (2014) Comparative study of commercial and palm oil empty fruit bunch fiber with preliminary study in the production of empty fruit bunch fiber cement board. Ph.D. thesis. Faculté des Sciences: Université de Douala-Cameroon

5. Laborel-Préneron A, Magniont C, Aubert J-E (2018) Characterization of barley straw, hemp shiv and corn cob as resources for bioaggregate based building materials. Waste Biomass Valoriz 9(7):1095-1112

6. Zuhri MYM, Sapuan SM, Ismail N, Wirawan R (2009) Mechanical properties of short random oil palm fibre reinforced epoxy composites. Sains Malays 39(1):87-92

7. Grégoire $M$, Ouagne $P$, Barthod-Malat B, Evon P, Labonne L, Placet V (2019) Extraction of linseed flax fibers for technical textiles: influence of pre-treatment parameters on the fiber yield, the mechanical properties and the mechanical properties. Rev Compos Mater Av 29(5):293-298. https://doi.org/10.18280/ rcma.290503

8. Amziane S, Collet F, Lawrence M, Magnion C, Picandet V (2017) Round robin test for hemp shiv characterisation: part 1 evaluation of initial water content and water absorption. Bio-aggregates based building materials, vol 23. Springer, Amsterdam. https://doi.org/10.1007/978-94-024-1031-0

9. Bono P, Le Duc A, Lozachmeur M, Day A (2015) Les nouveaux champs de recherche et développement pour la valorisation 
des fibers végétales techniques (lin fibers et chanvre). Oilseeds et fats Crops Lipids OCL 22(6):613. https://doi.org/10.1051/ ocl $/ 2015041$

10. Çomak B, Bideci A, Bideci OS (2018) Effects of hemp fibers on characteristics of cement based mortar. Constr Build Mater 169:794-799. https://doi.org/10.1016/j.conbuildma t.2018.03.029

11. Danso H, Manu D (2019) Influence of coconut fibers and lime on the properties of soil-cement mortar. Case Stud Constr Mater 12:e00316. https://doi.org/10.1016/j.cscm.2019.e00316

12. Kesikidou F, Stefanidou M (2019) Natural fiber-reinforced mortars. J Build Eng 25:100786. https://doi.org/10.1016/j. jobe.2019.100786

13. Ramakrishna G, Sundararajan T (2005) Impact strength of a few natural fiber reinforced cement mortar slabs: a comparative study. Cement Concr Compos 27:547-553. https://doi. org/10.1016/j.cemconcomp.2004.09.006

14. Vantadori S, Carpinteri A, Zanichelli A (2019) Lightweight construction materials: mortar reinforced with date-palm mesh fibers. Theor Appl Fract Mech 100:39-45. https://doi.org/10.1016/j. tafmec.2018.12.011
15. Venkateshwaran N, ElayaPerumal A (2012) Mechanical and water absorption properties of woven jute/banana hybrid composites. Fibers Polym 13:907-914. https://doi.org/10.1007/s1222 1-012-0907-0

16. Baley C, Busnel F, Grohens Y, Sire O (2006) Influence of chemical treatments on surface properties and adhesion of flax fiberpolyester resin. Compos Part A Appl Sci Manuf 37:1626-1637. https://doi.org/10.1016/j.compositesa.2005.10.014

17. Raut AN, Gomez CP (2016) Thermal and mechanical performance of oil palm fiber reinforced mortar utilizing palm oil fly ash as a complementary binder. Constr Build Mater 126:476483. https://doi.org/10.1016/j.conbuildmat.2016.09.034

Publisher's Note Springer Nature remains neutral with regard to jurisdictional claims in published maps and institutional affiliations. 